\title{
Long-term nasal intermittent positive pressure ventilation (NIPPV) in sixteen consecutive patients with bronchiectasis: a retrospective study
}

\author{
A. Gacouin, B. Desrues, H. Léna, M.L. Quinquenel, \\ J. Dassonville, Ph. Delaval
}

Long-term nasal intermittent positive pressure ventilation (NIPPV) in sixteen consecutive patients with bronchiectasis: a retrospective study. A. Gacouin, B. Desrues, H. Léna, M.L. Quinquenel, J. Dassonville, Ph. Delaval. @ERS Journals 1996.

ABSTRACT: Life expectancy and quality of life are poor in patients with chronic respiratory failure due to bronchiectasis. The indication for nocturnal nasal intermittent positive pressure ventilation (NIPPV) remains controversial in chronic obstructive lung disease. The purpose of the present study was to determine whether some of the objectives of home mechanical ventilation, i.e. improvement in blood gas values and reduced length of hospitalization, were fulfilled by NIPPV and oxygen plus medical treatment in patients with chronic respiratory failure due to bronchiectasis.

Sixteen consecutive patients (12 females and four males; mean age $57 \pm 11$ yrs) with chronic respiratory failure due to bronchiectasis, treated at home with nocturnal NIPPV in addition to oxygen therapy, were retrospectively studied in terms of blood gas values and duration of hospitalization before and after NIPPV. Details of the therapy received by each patient were recorded. Nine patients agreed to complete a questionnaire to determine their perception of the benefits of the treatment. NIPPV was performed using a volumetric respirator and was applied with a customized nasal mask modelled with silicone paste.

NIPPV was used for a mean of 26 months (range 0.5-60 months). Eleven patients were alive 12 months after use of NIPPV. No significant improvement in blood gas values was noted on room air during NIPPV, but arterial carbon dioxide tension $\left(\mathrm{Pa}_{\mathrm{a}}, \mathrm{CO}_{2}\right)$ stabilized after the period of worsening observed before initiation of NIPPV. Duration of hospitalization, the year before and the year after NIPPV, was 19 (3-40) and 16 (8-37) days, respectively (Ns). For the 11 patients who were alive 2 yrs after the start of NIPPV, duration of hospitalization the year before NIPPV and between 12 and 24 months after NIPPV were $17(4-40)$ and $7(2-27)$ days, respectively $(p<0.05)$. Nine patients who had received NIPPV for at least 12 months at the time of the study reported an improvement in their quality of life.

These results suggest that home ventilatory support by nasal intermittent positive pressure ventilation offers an acceptable alternative to tracheotomy, with less discomfort, in the management of severe respiratory failure due to bronchiectasis, in order to allow the patient to return home. These results should be confirmed by controlled studies.

Eur Respir J., 1996, 9, 1246-1250.
Dept of Respiratory Medicine, Hôpital Pontchaillou, Centre Hospitalier Régional et Universitaire, Rennes, France.

Correspondence: Ph. Delaval

Service de pneumologie

Hôpital Pontchaillou

CHRU de Rennes

35033 Rennes Cedex

France

Keywords: Bronchiectasis

home mechanical ventilation

nasal intermittent positive pressure

ventilation

Received: October 281994

Accepted after revision February 26 1996
Life expectancy and quality of life are poor in patients with chronic respiratory failure due to diffuse bronchiectasis who undergo tracheotomy [1]. Even if drainage is correctly conducted, some patients develop respiratory failure and long-term oxygen therapy is complicated by $\mathrm{CO}_{2}$ retention. Management with noninvasive ventilation avoids complications due to tracheotomy. In chronic restrictive respiratory failure, the use of noninvasive ventilation for only $6-8 \mathrm{~h}$ nightly improves respiratory status [2-4]. The efficacy of long-term ventilatory assistance by noninvasive ventilation remains controversial in patients with chronic obstructive pulmonary disease (COPD) [5-7].

The purpose of this retrospective study of patients with chronic respiratory failure due to bronchiectasis was to determine whether some of the objectives of home mechanical ventilation [8], i.e. improvement in blood gases, reduced length of hospitalization, were fulfilled by nocturnal NIPPV, as rescue therapy, plus oxygen and medical treatment. Details of the therapy received by each patient were recorded using a nonstandardized questionnaire.

Material and methods

\section{Patients}

From 1987 to 1993, nocturnal NIPPV was performed in sixteen patients (12 females, 4 males) with diffuse bronchiectasis. This retrospectively studied population represents all patients with bronchiectasis seen at the department of respiratory medicine for whom NIPPV was proposed as rescue therapy in order to provide home 
Table. 1. - Clinical details of patients prior to NIPPV

\begin{tabular}{|c|c|c|c|c|c|c|c|c|c|c|c|c|c|c|c|c|}
\hline \multirow{2}{*}{$\begin{array}{l}\text { Case } \\
\text { No. } \\
1^{\$}\end{array}$} & \multirow{2}{*}{$\begin{array}{c}\begin{array}{l}\text { Age } \\
\text { yrs }\end{array} \\
55\end{array}$} & \multirow{2}{*}{$\begin{array}{c}\text { Sex } \\
\text { F }\end{array}$} & \multirow{2}{*}{$\begin{array}{c}\begin{array}{c}\text { Weight } \\
\mathrm{kg}\end{array} \\
52\end{array}$} & \multirow{2}{*}{$\begin{array}{c}\begin{array}{c}\text { Height } \\
\mathrm{cm}\end{array} \\
156\end{array}$} & \multicolumn{2}{|c|}{$\begin{array}{c}P_{\mathrm{a}, \mathrm{CO}_{2}} \\
\mathrm{kPa} \mathrm{mmHg}\end{array}$} & \multicolumn{2}{|c|}{$\begin{array}{c}P_{\mathrm{a}, \mathrm{O}_{2}} \\
\mathrm{kPa} \mathrm{mmHg}\end{array}$} & \multirow{2}{*}{$\begin{array}{c}\mathrm{pH} \\
7.31\end{array}$} & \multirow{2}{*}{$\begin{array}{r}\begin{array}{r}\mathrm{Fl} \\
\mathrm{L} \cdot \mathrm{s}^{-1}\end{array} \\
1.20\end{array}$} & \multirow{2}{*}{$\begin{array}{l}\mathrm{EV} 1 \\
\% \text { pred }\end{array}$} & \multirow{2}{*}{$\begin{array}{c}\begin{array}{c}\text { FEV1/ } \\
\text { FVC }\end{array} \\
58\end{array}$} & \multicolumn{2}{|c|}{$\begin{array}{c}\mathrm{FVC} \\
\mathrm{L} \% \text { pred }\end{array}$} & \multicolumn{2}{|c|}{$\begin{array}{l}\mathrm{RV} \\
\mathrm{L} \% \text { pred }\end{array}$} \\
\hline & & & & & 8.0 & 60 & 4.7 & 35 & & & & & 2.01 & 69 & 1.47 & 85 \\
\hline 2 & 59 & $\mathrm{~F}$ & 44 & 149 & 9.2 & 69 & 4.9 & 37 & 7.37 & 0.36 & 20 & 34 & 1.06 & 37 & 1.55 & 100 \\
\hline $3^{\$}$ & 48 & $\mathrm{~F}$ & 43 & 154 & 7.7 & 58 & 10.1 & 76 & 7.31 & 0.91 & 38 & 41 & 2.00 & 65 & 1.40 & 73 \\
\hline 4 & 64 & $\mathrm{~F}$ & 62 & 157 & 8.0 & 60 & 5.2 & 39 & 7.31 & 0.74 & 38 & 39 & 1.89 & 69 & 2.27 & 135 \\
\hline 5 & 67 & $\mathrm{~F}$ & 48 & 152 & 10.3 & 77 & 7.9 & 59 & 7.39 & 0.44 & 30 & 54 & 0.82 & 44 & 1.80 & 105 \\
\hline 6 & 49 & M & 51 & 160 & 8.4 & 63 & 4.8 & 36 & 7.31 & 0.96 & 33 & 59 & 1.40 & 42 & 1.70 & 86 \\
\hline 7 & 61 & $\mathrm{~F}$ & 48 & 155 & 8.3 & 62 & 7.5 & 56 & 7.30 & 0.69 & 34 & 46 & 1.50 & 59 & 1.96 & 116 \\
\hline $8^{\$}$ & 54 & $\mathrm{~F}$ & 52 & 154 & 7.7 & 58 & 7.6 & 57 & 7.32 & 0.32 & 16 & 37 & 0.59 & 24 & 1.30 & 78 \\
\hline 9 & 48 & $\mathrm{M}$ & 46 & 158 & 7.2 & 54 & 6.1 & 46 & 7.34 & 0.73 & 33 & 52 & 2.00 & 45 & 1.84 & 90 \\
\hline 10 & 33 & $\mathrm{~F}$ & 47 & 153 & 8.3 & 62 & 6.0 & 45 & 7.40 & 0.72 & 27 & 27 & 1.27 & 41 & 1.30 & 92 \\
\hline $11^{+}$ & 65 & $\mathrm{~F}$ & 60 & 158 & 6.5 & 49 & 5.3 & 40 & 7.37 & 0.43 & 21 & 24 & 1.82 & 71 & 2.51 & 134 \\
\hline 12 & 78 & $\mathrm{~F}$ & 51 & 160 & 6.8 & 51 & 8.0 & 60 & 7.37 & NA & NA & NA & NA & NA & NA & NA \\
\hline 13 & 68 & $\mathrm{M}$ & 80 & 155 & 6.7 & 50 & 8.0 & 60 & 7.36 & 0.76 & 34 & 51 & 1.48 & 52 & 2.05 & 91 \\
\hline 14 & 55 & $\mathrm{~F}$ & 40 & 156 & 8.9 & 67 & 6.4 & 48 & 7.30 & 1.13 & 52 & 73 & 1.55 & 61 & 1.70 & 99 \\
\hline $15^{+}$ & 61 & $\mathrm{~F}$ & 74 & 150 & 8.1 & 61 & 6.4 & 48 & 7.36 & NA & NA & NA & NA & NA & NA & NA \\
\hline 16 & 40 & $\mathrm{M}$ & 55 & 177 & 6.8 & 51 & 6.7 & 50 & 7.37 & 1.36 & 38 & 58 & 2.04 & 48 & 1.02 & 56 \\
\hline Mean & 57 & & 53 & 156 & 8.0 & 60 & 6.7 & 50 & 7.34 & 0.77 & 35 & 47 & 1.48 & 51 & 1.71 & 95 \\
\hline SD & \pm 11 & & \pm 11 & \pm 4 & 1.2 & \pm 9 & 1.7 & \pm 11 & \pm 0.04 & \pm 0.32 & 14 & \pm 14 & \pm 0.45 & 15 & \pm 0.41 & 22 \\
\hline
\end{tabular}

$\mathrm{Pa}_{\mathrm{a}} \mathrm{O}_{2}, \mathrm{~Pa}_{\mathrm{a}} \mathrm{CO}_{2}$ and $\mathrm{pH}$ are values recorded whilst breathing room air when NIPPV was decided. FEV1, FEV1/FVC, FVC and RV are values recorded in the 6 months before NIPPV. NIPPV: nasal intermittent positive pressure ventilation; F: female; M: male; FEV1: forced expiratory volume in one second; $\mathrm{FVC}$ : forced vital capacity; $\mathrm{RV}$ : residual volume; $P_{\mathrm{a}, \mathrm{O}_{2}}$ : arterial oxygen tension; $P \mathrm{a}, \mathrm{CO}_{2}$ : arterial carbon dioxide tension; \% pred: percentage of predicted value; NA: results not available because of incorrect performance of the test. \$: patient died before one year of ventilation; +: patient died during the study, after NIPPV for more than 12 months.

ventilatory support (table 1). All patients had a history of cough and sputum production since childhood, with the exception of patients Nos. 4 and 8. Patients Nos. 9, 13 and 16 were smokers (less than 10 cigarettes $\cdot$ day $^{-1}$ ). The aetiology of bronchiectasis was: pertussis (patients Nos. 3, 5-7 and 14); measles (No. 15); recurrent infections due to Buckley syndrome (No. 10); and lung abscess (No. 8). Rheumatoid arthritis was associated with bronchiectasis in patients Nos. 2 and 11. Thirteen patients had previously used home oxygen therapy (the exceptions being patients Nos. 1, 3 and 5) for an average of 25 months (3-65 months). In spite of episodes of acute respiratory failure, patients No. 3 and 5 refused home oxygen and medical care. Of the 13 patients, five received oxygen for less than 3 months (Nos. 8, 9, 13, 14 and 16). The spirometric values reported (Jaeger Flowscreen, Germany) were obtained from patients in respiratory steadystate in the 6 months preceding the initiation of NIPPV. Echocardiography, performed in 13 patients in the 6 months before NIPPV was started, showed right ventricular dilation or hypertrophy and confirmed pulmonary hypertension in four. Fourteen patients had a computed tomography (CT) scan which showed bronchiectasis involving 2-5 lobes (mean 3.5 lobes). Bronchiectasis involved; right and left lower lobes in patients Nos. 2 and 8-10; the five lobes in Nos. 3-6 and 14; the middle lobe and inferior lingula in Nos. 13 and 15; and the superior and inferior lingula in No. 11.

\section{Nasal ventilation}

Individual nasal masks were made by modelling a mixture of silicone paste and catalyst on the patient's nose. Two types of volumetric ventilator were used: Monnal D (Air Liquide, France) or EOLE 2 (SAIME, France) operated in the control mode. The intention was to give nocturnal NIPPV and to continue oxygen therapy during the day. Tidal volumes $(V \mathrm{~T})$ used were greater than during mechanical ventilation to compensate for leaks through the mouth ( $V \mathrm{~T}$ 20-30 $\mathrm{mL} \cdot \mathrm{kg}^{-1}$; inspiratory/expiratory (I/E) ratio 1/2). The flow rate was progressively adapted to obtain 15-25 breaths $\mathrm{min}^{-1}$, by modification of $V \mathrm{~T}$ and $\mathrm{I} / \mathrm{E}$, depending upon the patient's comfort and blood gas values. All patients had added oxygen during nocturnal NIPPV to maintain their oxygen saturation greater than $90 \%$. Nasal oxygen therapy was also administered during the daytime. Oxygen supplementation was achieved with a concentrator (MC 44, DeVilbiss, USA; Zefir, Air Liquide, France; Companion 492, Puritan Benett, USA). There was no humidifier in the breathing circuit. The first objective at the initiation of NIPPV was not to normalize blood gas values, but to enable patients to tolerate overnight NIPPV. However, at the same time, a nonsignificant decrease in arterial oxygen tension $\left(\mathrm{Pa}_{\mathrm{a}}, \mathrm{CO}_{2}\right)$ was noted after $1 \mathrm{~h}$ of NIPPV in comparison with $P \mathrm{a}, \mathrm{CO}_{2}$ values in room air before NIPPV $(8.0 \pm 1.1$ and $7.7 \pm 1.4$ $\mathrm{kPa}(60.1 \pm 8.6$ and $58 \pm 10.7 \mathrm{mmHg})$, respectively). After the initial stabilization period in the hospital, all patients were discharged. The follow-up of these patients was the same as for other patients in our department treated by home ventilatory support.

\section{Objectives studied}

When available, the following parameters were compared 1) arterial blood gas values whilst breathing room air at the time of NIPPV initiation, with values recorded 12 and 6 months before NIPPV was started and with values obtained after 1, 3, 6, 12 and 24 months of NIPPV; 2) pulmonary function tests in respiratory steady-state between 18 and 12 months before NIPPV, in the six months preceding NIPPV, and after 1 year of NIPPV; and 3) the number of days in hospital during the year before and the 2 yrs following initiation of NIPPV. Nine patients were still alive at the time of the study and all 
Table 2. - Individual data of patients with progressive worsening of respiratory failure

\begin{tabular}{|c|c|c|c|c|c|c|c|c|}
\hline \multirow{2}{*}{$\begin{array}{l}\text { Case } \\
\text { No. }\end{array}$} & \multicolumn{4}{|c|}{$\mathrm{Pa}_{\mathrm{a}, \mathrm{O}_{2}} \mathrm{mmHg}$} & \multicolumn{4}{|c|}{$P_{\mathrm{a}, \mathrm{CO}_{2}} \mathrm{mmHg}$} \\
\hline & $-12 \mathrm{M}$ & $-6 M$ & Admission & Start NIPPV* & -12 & $-6 M$ & Admission & Start NIPPV* \\
\hline 2 & 51 & 50 & 44 & 45 & 55 & 55 & 68 & 70 \\
\hline 4 & 56 & 55 & 40 & 40 & 50 & 52 & 60 & 63 \\
\hline 6 & 55 & 37 & 64 & 61 & 50 & 58 & 58 & 59 \\
\hline 7 & 51 & 61 & 46 & 57 & 56 & 51 & 65 & 67 \\
\hline 8 & NA & 49 & 60 & 61 & NA & 54 & 59 & 61 \\
\hline 9 & 50 & 55 & 64 & 62 & 55 & 65 & 52 & 58 \\
\hline 10 & 59 & 58 & 68 & 70 & 48 & 56 & 69 & 68 \\
\hline 12 & 53 & 55 & 66 & 67 & 46 & 49 & 50 & 49 \\
\hline 13 & 61 & NA & 60 & 61 & 55 & NA & 51 & 51 \\
\hline 14 & NA & NA & 57 & 58 & NA & NA & 60 & 64 \\
\hline 15 & 52 & 51 & 54 & 55 & 53 & 55 & 72 & 71 \\
\hline 16 & 59 & 58 & 60 & 55 & 44 & 49 & 53 & 53 \\
\hline Mean & 57 & 53 & 56 & 57 & 51 & 54 & 59 & 60 \\
\hline$\pm \mathrm{SD}$ & \pm 3 & \pm 6 & \pm 9 & \pm 8 & \pm 4 & \pm 4 & \pm 8 & \pm 7 \\
\hline
\end{tabular}

Arterial blood gas values were measured 12 and 6 months before NIPPV, at hospital admission and at the start of NIPPV. A mean $( \pm \mathrm{SD})$ of $10 \pm 6$ days separated the admission and the start of NIPPV. *: because of the intensive medical treatment, blood gases were measured on oxygen. $7.5006 \mathrm{mmHg}=1 \mathrm{kPa}$. NA: data not available; M: months. For further abbreviations see legend to table 1 .

of them agreed to complete a questionnaire consisting of open questions [9], to determine their perception of the benefits of the treatment. The first part of this questionnaire was designed to determine whether symptoms possibly related to chronic respiratory failure regressed with NIPPV. The second part concerned, in particular, the compliance and the acceptability of nasal ventilation.

\section{Statistical analysis}

Analysis of variance (ANOVA) was used for repeated measures and the Fisher test for pairwise comparisons. The Wilcoxon test was used to compare the duration of hospitalization before and after NIPPV. Values are expressed as mean $\pm \mathrm{SD}$. Differences were considered significant at p-values less than 0.05 .

\section{Results}

\section{General characteristics of the population}

The proposed NIPPV was accepted by all patients and was used for a mean of 26 months (0.5-60 months). Three patients died during the first two yrs of ventilation. Patient No. 1 was admitted with acute respiratory failure. Because of the patients condition, endotracheal ventilation was not applied, and the patient died after 15 days of NIPPV. Patients Nos. 3 and 8 died of respiratory failure after 11 months of NIPPV, and No. 15 died after 15 months of NIPPV. One patient (No. 11) died after 48 months of NIPPV. One patient (No. 14), who moved to another region, was lost to follow-up 3 weeks after the initiation of NIPPV. All patients had severe respiratory insufficiency with a mean $( \pm \mathrm{SD})$ baseline forced expiratory volume in one second (FEV1) of $0.77 \pm 0.32$ $\mathrm{L}$ and forced vital capacity (FVC) of $1.48 \pm 0.45 \mathrm{~L}$ (table 1).

\section{Effects of NIPPV on blood gas values}

Before institution of NIPPV, most patients experience progressive hypercapnic failure in spite of standard intensive medical treatment, including chest physiotherapy, brochodilators, antibiotics and long-term oxygen therapy. For the overall population, 12 and 6 months before NIPPV, we observed a progressive worsening of chronic respiratory failure with an increase in $P \mathrm{a}, \mathrm{CO}_{2}$ from $6.7 \pm 0.3$ to $8.0 \pm 1.2 \mathrm{kPa}(50.5 \pm 2.6$ to $60.1 \pm 8.7 \mathrm{mmHg})(\mathrm{p}<0.05)$. For patients Nos. 1, 3, 5 and 11, NIPPV was implemented because of an acute exacerbation or difficulties of weaning from mechanical ventilation. For the other 12 patients, NIPPV was initiated because intensive medical treatment in hospital was ineffective in alleviating respiratory symptoms and progressive respiratory failure. At admission, these patients did not present with acute respiratory failure or pulmonary infection. Between the first day of hospitalization and the initiation of NIPPV (10 \pm 6 days), $P \mathrm{a}_{1} \mathrm{CO}_{2}$ did not worsen (table 2 ).

In the overall population, after initiation of NIPPV, $P \mathrm{a}, \mathrm{CO}_{2}$ tended to decrease and arterial oxygen tension $\left(\mathrm{Pa}, \mathrm{O}_{2}\right)$ to increase, but no statistically significant difference could be observed between $P$ a, $\mathrm{CO}_{2}$ and $\mathrm{Pa}, \mathrm{O}_{2}$ values in room air at 1, 3, 6, 12 and 24 months (fig. 1).

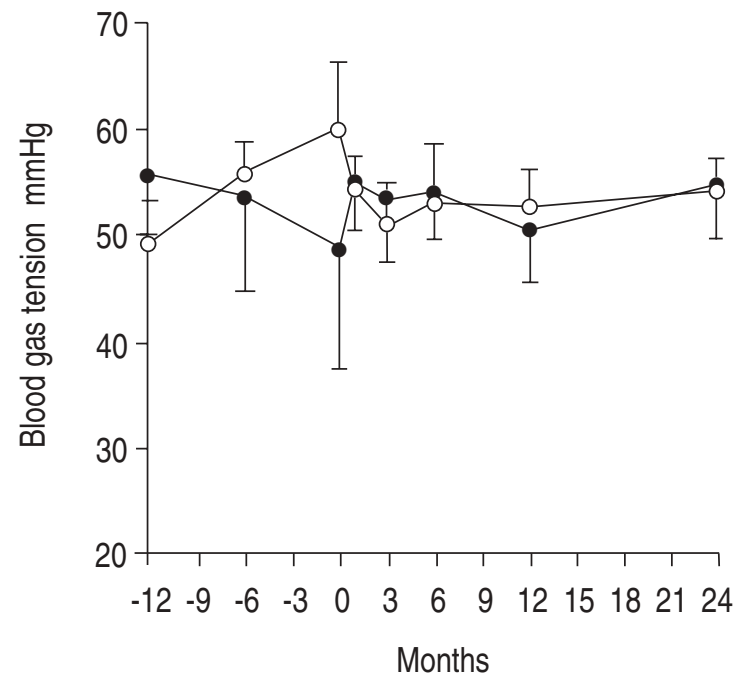

Fig. 1. - Changes in arterial carbon dioxide tension $\left(\mathrm{Pa}_{2}, \mathrm{CO}_{2}\right)$ and arterial oxygen tension $\left(\mathrm{Pa}_{\mathrm{a}} \mathrm{O}_{2}\right)$ on air. $\longrightarrow \mathrm{O}-\mathrm{Pa}, \mathrm{CO}_{2} ; \longrightarrow \longrightarrow: \mathrm{Pa}, \mathrm{O}_{2} .7 .5006$ $\mathrm{mmHg}=1 \mathrm{kPa}$. 


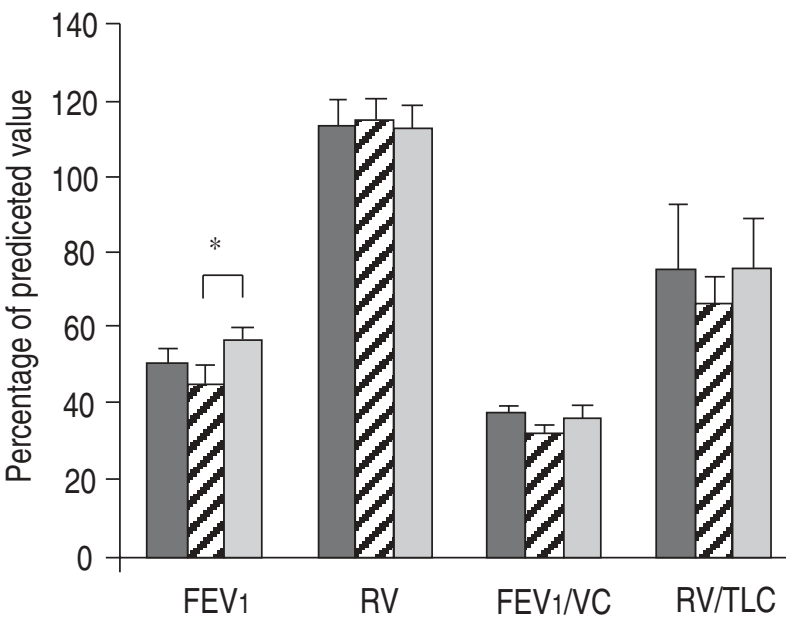

Fig. 2. - Changes in pulmonary function tests in the steady-state : 18-12 months before NIPPV; $\square: 12-6$ months before NIPPV; during NIPPV. FEV1: forced expiratory volume in one second; $\mathrm{RV}$ : residual volume; FEV1/VC: FEV1 as percentage of vital capacity; TLC: total lung capacity; NIPPV: nasal intermittent positive pressure ventilation *: $\mathrm{p}<0.05$.

However, $\mathrm{Pa}, \mathrm{CO}_{2}$ and $\mathrm{Pa}, \mathrm{O}_{2}$ remained stable for 24 months after initiation of NIPPV.

\section{Effects of NIPPV on pulmonary function tests}

FEV1 and FEV1/FVC tended to decrease before NIPPV. No significant change in pulmonary function was seen $1 \mathrm{yr}$ after the start of NIPPV, except for FEV1, which was significantly increased (fig. 2).

Table 3. - Hospitalization

\begin{tabular}{|c|c|c|c|c|c|c|c|c|}
\hline \multirow[t]{2}{*}{$\begin{array}{l}\text { Case } \\
\text { No. }\end{array}$} & \multirow{2}{*}{$\begin{array}{c}\text { Before } \\
\text { NIPPV } \\
\text { days }\end{array}$} & \multicolumn{4}{|c|}{ During NIPPV } & \multicolumn{3}{|c|}{ days } \\
\hline & & A & B & $\mathrm{C}$ & $\mathrm{T}$ & A & $\mathrm{C}$ & $\mathrm{T}$ \\
\hline 1 & 40 & 15 & & & & & & \\
\hline 2 & 20 & 14 & 4 & 12 & 30 & 4 & 0 & 4 \\
\hline $3 *$ & 20 & 7 & 2 & 0 & 9 & & & \\
\hline 4 & 40 & 6 & 1 & 19 & 26 & 3 & 24 & 27 \\
\hline 5 & 28 & 4 & 4 & 0 & 8 & 2 & 0 & 2 \\
\hline 6 & 14 & 30 & 3 & 4 & 37 & 4 & 0 & 4 \\
\hline 7 & 4 & 4 & 4 & 0 & 8 & 2 & 0 & 2 \\
\hline $8 *$ & 30 & 5 & 2 & 13 & 20 & & & \\
\hline 9 & 28 & 6 & 4 & 0 & 10 & 3 & 0 & 3 \\
\hline 10 & 15 & 9 & 4 & 0 & 13 & 2 & 0 & 2 \\
\hline 11 & 20 & 5 & 4 & 0 & 9 & 3 & 4 & 7 \\
\hline 12 & 5 & 5 & 4 & 0 & 9 & 3 & 16 & 19 \\
\hline 13 & 10 & 4 & 4 & 0 & 8 & 2 & 0 & 2 \\
\hline 14 & NA & 7 & $?$ & $?$ & $?$ & $?$ & $?$ & $?$ \\
\hline $15^{\$}$ & 30 & 4 & 3 & 9 & 16 & & & \\
\hline 16 & 3 & 11 & 4 & 5 & 20 & 2 & 0 & 2 \\
\hline
\end{tabular}

A: number of days in hospital between the start of NIPPV and discharge; B: number of days in hospital related to routine measurements of blood gas values; $\mathrm{C}$ : number of days in hospital due to worsening of respiratory status; $\mathrm{T}$ : total number of days in hospital during the year. *: patient died after 11 months of NIPPV, but considered as if NIPPV was performend for the entire year for comparison of days of hospitalization before and during the the first year of NIPPV; $\$$ : patient died 15 months after start of NIPPV; ?: patient lost to follow-up. NIPPV: nasal intermittent positive pressure ventilation. NA: data not avialable.

\section{Hospitalizations (table 3)}

For patients alive 12 months after onset of NIPPV, the duration of hospitalization before and during NIPPV was $19 \pm 11$ and $16 \pm 9$ days, respectively (NS). Instruction of patients required $5 \pm 2$ days. However, for patients who were alive after 24 months of NIPPV, the duration of hospitalization was significantly decreased during the second year of follow-up (17 \pm 12 days before and $7 \pm 8$ days during NIPPV, respectively; $\mathrm{p}<0.05$ ).

\section{Questionnaire responses}

NIPPV was well-tolerated but one patient developed conjunctivitis. No patient complained of nasal congestion in spite of chronic sinusitis (confirmed by radiological opacification of paranasal sinus) in all of them. Six patients had previous symptoms of chronic alveolar hypoventilation, which resolved with NIPPV in three. All reported improvement in terms of the quality of sleep and in level of daytime activity. Eight patients considered that the improvement in their respiratory status outweighed any discomfort due to NIPPV. In order to assess compliance with NIPPV, the daily duration of ventilation was noted by reading the recording device; it was a mean $10 \mathrm{~h} \cdot \mathrm{day}^{-1}\left(6-15 \mathrm{~h} \cdot \mathrm{day}^{-1}\right)$.

\section{Discussion}

We report our experience in home ventilatory support by nocturnal NIPPV as a rescue therapy in patients with severe diffuse bronchiectasis for whom medical treatment alone failed to control the progressive increase in $\mathrm{CO}_{2}$ retention (fig. 1). We found no long-term significant improvement in blood gas values in room air, nor significant reduction in days spent in hospital. An improvement in daytime level of activity was reported by patients. There were limitations to our study design (small size of the population, absence of control group) and a prospective, randomized, controlled study design would have been preferable. However, the number of patients with chronic hypercapnic respiratory failure due to bronchiectasis is small and controlled studies are, therefore, difficult to achieve in this particular population.

The absence of significant long-term improvement in blood gas values is disappointing. However, it should be noted that there was no significant worsening of the values with NIPPV. The absence of significant worsening of functional data, in particular FEV1, is a second argument suggesting that NIPPV helps to stabilize patients. Thus, NIPPV and medical treatment dramatically slow the respiratory decline. During the first year of NIPPV there was a trend to a reduction in the number of days spent in hospital, but this reduction was not significant. However, it should be noted that hospitalization during NIPPV included days required for instruction of patients. Also for three patients (Nos. 7, 12 and 16), the absence of previous hospitalization was probably more the consequence of inadequate medical support than a healthy condition. In contrast, for patients who were alive the second year after the start of NIPPV, there was a significant decrease in the length of hospitalization. 
Quality of life was better with NIPPV; thus, the acceptability of NIPPV was good and none of the patients gave up NIPPV because of nasal congestion, in spite of chronic sinusitis. No significant factor was found which was predictive of the success (i.e. duration of ventilation longer than 12 months) of NIPPV in terms of age or blood gas values at the start of ventilation.

The fact that all patients, except No. 1, could return home is an important point in favour of improvement in the quality of life. It is possible that the improvement reported by patients was a result of closer medical supervision, but it should be noted that, compared to preNIPPV, there was no increase in the frequency of medical visits to the department. We, therefore, do not believe that this can explain the long-term acceptability of NIPPV. The desire of all patients, after more than one year of NIPPV, to continue using nocturnal NIPPV suggests a benefit. Several patients stated that sputum production decreased with NIPPV. Six patients declared that with nasal ventilation they were no longer receiving antibiotic treatment. These benefits parallel those reported by other authors who offered NIPPV to patients with cystic fibrosis [10]. We did not test expiratory muscle strength, but we suppose, like other authors, that the intermittent rest of expiratory muscle may contribute to a more effective cough. By protecting the natural clearance of airway secretion, long-term NIPPV has the advantage of not hindering the management of bronchial toilette. In contrast, in acute respiratory failure, hypersecretion makes the use of invasive ventilation preferable because of the risk of atelectasis [11].

Ventilation via tracheotomy has also been used in these patients, but there are significant medical and psychological problems associated with long-term tracheotomy. There are few data concerning the prognosis of patients with bronchiectasis treated by tracheotomy with home mechanical ventilation, but nevertheless survival at $2 \mathrm{yrs}$ can be estimated as 50-60\%, [1]. In our study, 11 patients were alive after 24 months of NIPPV (actuarial survival at 2 yrs $=68 \%$ ). We can suppose, but not assert, from this uncontrolled study, that the prognosis of patients treated by NIPPV is not-very different from the prognosis of patients treated by tracheotomy, and NIPPV is probably more comfortable.

Our data are consistent with those published recently by LEGER et al. [12], who retrospectively evaluated longterm NIPPV in 276 patients with respiratory failure of diverse aetiologies. Of these patients, 25 had bronchiectasis and 6 were evaluable after 24 months of NIPPV. No significant differences were seen in terms of blood gas values or pulmonary function tests. The clinical characteristics of patients were not detailed in this study.

In conclusion, our data suggest that in severe chronic respiratory failure due to bronchiectasis, home ventilatory support by nasal intermittent positive pressure ventilation could be proposed as a rescue therapy for patients with progressive worsening of blood gas values in spite of optimum medical treatment. Our data suggest that nasal intermittent positive pressure ventilation in bronchiectasis is well-tolerated in spite of sinusitis, stabilizes respiratory status, and tends to reduce the number of days spent in hospital. These results should be confirmed by controlled studies.

Acknowledgements: The authors wish to express appreciation to J.M Arrechaga for skilful technical assistance.

\section{References}

1. Gay PC, Patel AM, Viggiano RW, Hubmayr RD. Nocturnal nasal ventilation for treatment of patients with hypercapnic respiratory failure. Mayo Clin Proc 1991; 66: 695-703.

2. Ellis RE, Bye PT, Brudere JW, Sullivan CE. Treatment of respiratory failure during sleep in patients with neuromuscular disease: positive-pressure ventilation through a nose mask. Am Rev Respir Dis 1987; 135: 148-152.

3. Ellis ER, Grunstein RR, Chan S, Bye PT, Sullivan CE. Noninvasive ventilatory support during sleep improves respiratory failure in kyphoscoliosis. Chest 1988; 94: 811-815.

4. Bach JR, Alba SA. Management of chronic alveolar hypertension by nasal ventilation. Chest 1990; 97: 52-57.

5. Elliot MW, Simonds AK, Carroll MP, Wedzicha JA, Branthwaite MA. Domiciliary nocturnal nasal intermittent positive pressure ventilation in hypercapnic respiratory failure due to chronic obstructive lung disease: effects on sleep and quality of life. Thorax 1992; 47: 342-348.

6. Strumpf DA, Millman RP, Carisle CC, et al. Nocturnal positive-pressure ventilation via nasal mask in patients with severe chronic obstructive pulmonary disease. Am Rev Respir Dis 1991; 144: 1234-1239.

7. Gutierrez M, Berioza T, Contreras G, et al. Weekly cuirass ventilation improves blood gases and inspiratory muscle strength in patients with chronic airflow limitation and hypercarbia. Am Rev Respir Dis 1988; 138: 617-623.

8. Branthwait MA. Home mechanical ventilation. Eur Respir $J$ 1990; 3: 743-745.

9. Desrues B, Lecoq C, and Air Bretagne. Observance et prescription de l'oxygenothérapie de longue durée. Rev Mal Resp 1989, 6; 237-241.

10. Piper AJ, Parker S, Tonillo JP, Sullivan CE, Bye PTP. Nocturnal nasal IPPV stabilizes patients with cystic fibrosis and hypercapnic respiratory failure. Chest 1992; 102: 846-450.

11. Benhamou D, Girault C, Faure C, Portier F, Muir JF. Nasal mask in acute respiratory failure-experience in elderly patients. Chest 1992; 102: 912-917.

12. Leger P, Bedicam JM, Cornette A, et al. Nasal intermittent positive pressure ventilation - Long-term followup in patients with chronic respiratory insufficiency. Chest 1994; 105: 100-105. 